
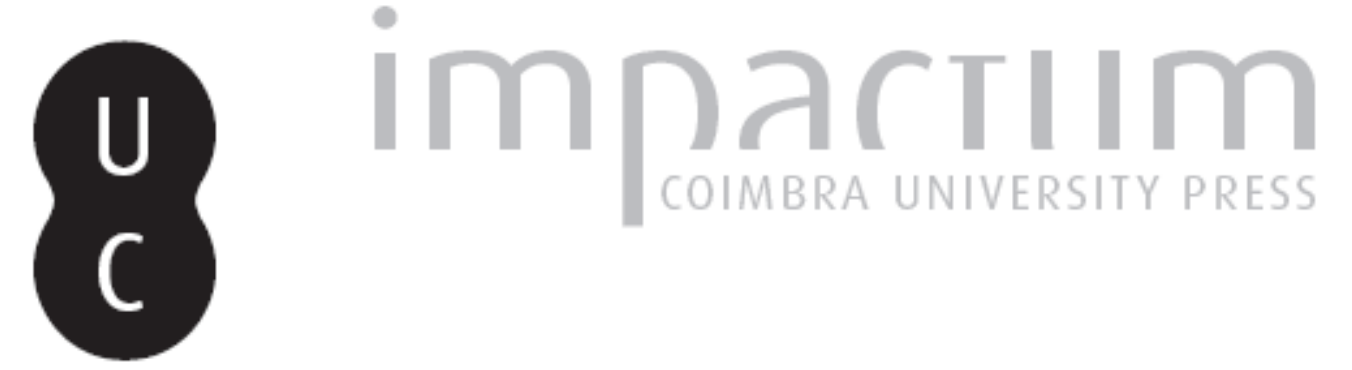

\title{
[Recensão a] BENOIT, H. (2015). PLATÃO E AS TEMPORALIDADES: A QUESTÃO METODOLÓGICA
}

Autor(es): $\quad$ Souza, Eliane de

Publicado por: Annablume Clássica; Imprensa da Universidade de Coimbra

URL persistente:

URI:http://hdl.handle.net/10316.2/38307

DOI:

DOI:http://dx.doi.org/10.14195/1984-249X_16_12

Accessed : $\quad$ 26-Apr-2023 09:07:37

A navegação consulta e descarregamento dos títulos inseridos nas Bibliotecas Digitais UC Digitalis, UC Pombalina e UC Impactum, pressupõem a aceitação plena e sem reservas dos Termos e Condições de Uso destas Bibliotecas Digitais, disponíveis em https://digitalis.uc.pt/pt-pt/termos.

Conforme exposto nos referidos Termos e Condições de Uso, o descarregamento de títulos de acesso restrito requer uma licença válida de autorização devendo o utilizador aceder ao(s) documento(s) a partir de um endereço de IP da instituição detentora da supramencionada licença.

Ao utilizador é apenas permitido o descarregamento para uso pessoal, pelo que o emprego do(s) título(s) descarregado(s) para outro fim, designadamente comercial, carece de autorização do respetivo autor ou editor da obra.

Na medida em que todas as obras da UC Digitalis se encontram protegidas pelo Código do Direito de Autor e Direitos Conexos e demais legislação aplicável, toda a cópia, parcial ou total, deste documento, nos casos em que é legalmente admitida, deverá conter ou fazer-se acompanhar por este aviso.

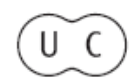


16

jan/apr

2016

issn 2179-4960

e-issn 1984-249X

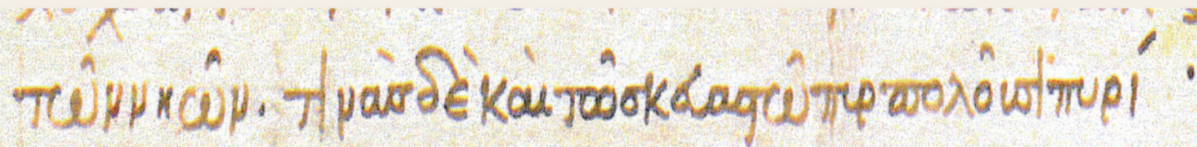

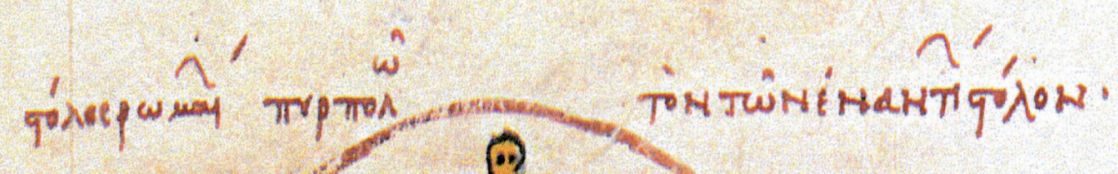
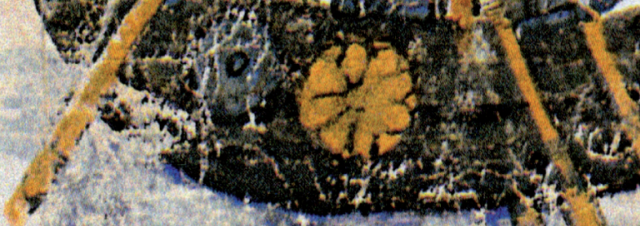

,

.
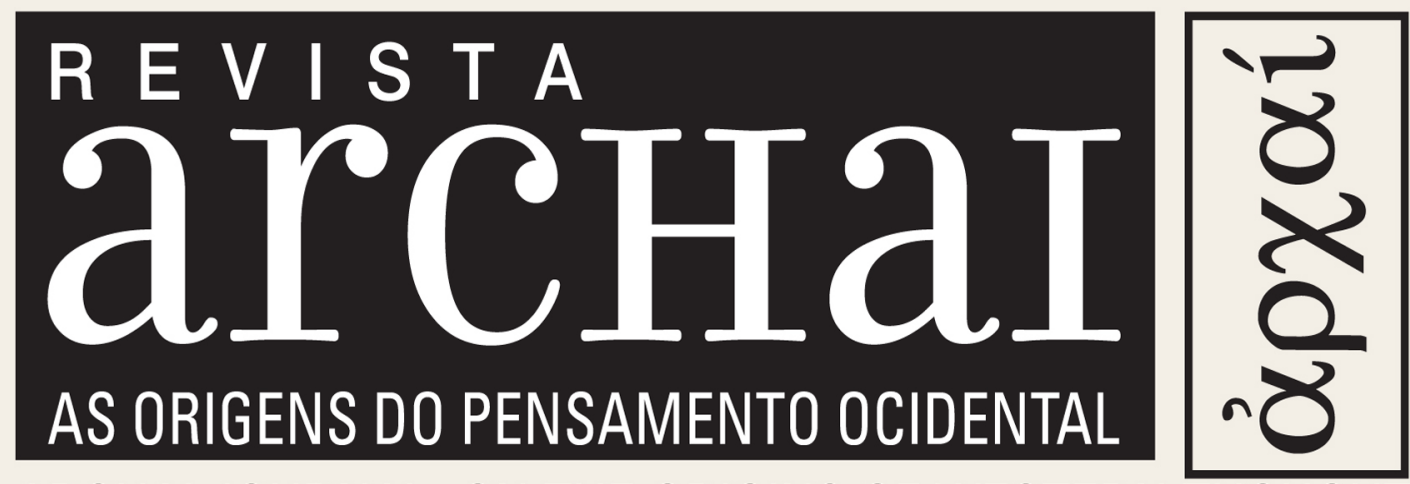

ARCHAI JOURNAL: ON THE ORIGINS OF WESTERN THOUGHT

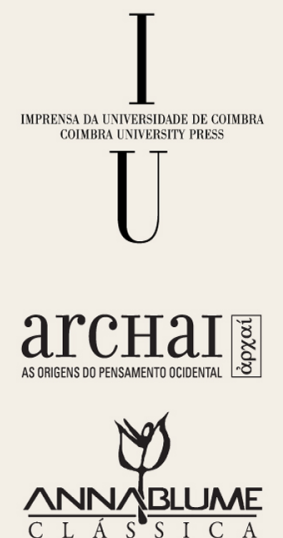




\section{BENOIT, H. (2015). PLATÃO E AS TEMPORALIDADES: A QUESTÃO METODOLÓGICA. SÃO PAULO, ANNABLUME.}

SOUZA, E. de (2016). Resenha: Benoit, H. (2015). Platão e as temporalidades: a questão metodológica. São Paulo, Annablume. Archai, n. 16, jan.-apr., p. 213-218

DOI: http://dx.doi.org/10.14195/1984-249X_16_12

Foi finalmente publicada a primeira parte da tese de Livre Docência em Filosofia de Hector Benoit, defendida em 2004 no Instituto de Filosofia e Ciências Humanas da Universidade Estadual de Campinas. O trabalho original era uma tetralogia dramática e, para fins de publicação, foi dividido em duas partes. Benoit apresenta, nessa primeira parte, um trabalho metodológico que serve como preparação para a publicação futura do romance filosófico A odisseia de Platão, mas que pode também ser lido como um livro autônomo.

O livro, que conta com apresentação do professor Arlei Moreno, da Unicamp, procura aproximar o leitor da situação de um leigo que lê Platão sem nenhuma informação, suspendendo os pressupostos teóricos que envolvem o texto dos diálogos e afastando-o da metafísica ocidental. 


\section{arcHaI \\ AS ORIGENS DO PENSAMENTO OCDENTA}

n. 16, jan.-apr. 2016

SOUZA, E. de, Benoit, H. (2015). Platão e as temporalidades: $a$ questão metodológica. São Paulo, Annablume. p. 213-218
A proposta é deixar de lado a ideia de que Platão é o autor supremo de uma doutrina sistemática e começar a ver a cena dos diálogos como análoga à da poesia homérica e trágica. Nesse sentido, o livro tem um caráter negativo, ao colocar em suspensão as interpretações que impedem a aproximação a um Platão conceitualmente poético. Seu intuito é preparar o leitor para ler os diálogos sem o recurso da tradição interpretativa, o que permite contemplar a sua lexis (modo de exposição). A disposição ordenada dos textos em uma temporalidade construída com os elementos léxicos revolucionaria a interpretação desses textos e o processo hermenêutico de toda a história da filosofia, segundo Benoit.

O livro é dividido em cinco capítulos. O capítulo 1, Platão e a poética do logos, levanta a questão da relação entre discurso filosófico e poesia a partir do logos de Platão, questão que, segundo o autor, não foi bem compreendida até hoje, nem mesmo por Heidegger. O problema passa a ser investigado a partir de um histórico de narrações que relatam Platão como sendo inicialmente um poeta e que, ao se tornar discípulo de Sócrates, se afasta da poesia e se transforma em seu inimigo. Esse percurso biográfico de Platão, que Benoit considera lendário, foi divulgado por Apuleu no século II d.C., sustentado no neoplatonismo por Proclus no século V d.C. e relatado no manual anônimo Prolegomena, texto do século VI d.C. A descrição de Platão como crítico da poesia perdura até Nietzsche, causando, na interpretação do texto platônico, uma tensão entre arte, moral e metafísica. Essa tensão se repete em Heidegger e permanece na maioria dos comentários contemporâneos que se referem a Platão como aquele que expulsou os poetas da cidade, dentre os quais Havelock. Graças a esse tipo de interpretação, até artistas e pensadores de vanguarda se voltaram contra Platão, mostra Benoit. O autor coloca uma dúvida: como é possível que Platão tenha tentado destruir a poesia e, ao mesmo tempo, tenha escrito obras filosóficas que são também estéticas e dramáticas?

Benoit considera que não existe diálogo que seja propriamente narrativo. Todos os diálogos são dramas não narrados diretamente ao leitor, mesmo aqueles que a tradição reconheceu como narrativos. Como exemplo, faz um exame do Protágoras, do Cármides e da República para mostrar que são diálogos e não narrações, como se costuma interpretar. Se os diálogos forem lidos a partir da forma dramática e da imitação, propõe, a obra de Platão se aproxima da lexis poética da tragédia e da comédia. Os diálogos seriam então uma das formas supremas da arte grega.

Para Benoit, a cena da metafísica ocidental é uma visão exterior da obra. Nietzsche, ao pretender romper com essa cena, paradoxalmente encontra na filosofia de Platão seu alicerce. A dúvida do autor é até que ponto se pode aceitar essa posição de Nietzsche e de seus seguidores. O livro é um esforço metodológico para mostrar que as acusações de que Platão expulsou os poetas e a poesia da cidade se fundamentam em uma tradição interpretativa duvidosa, da qual Benoit acredita que ainda 
não nos libertamos. Em vez de excluir a poesia, o autor opta por seguir a lexis platônica em busca da construção conceitualmente poética das temporalidades presentes em seu pensamento.

No capítulo 2, Os diálogos entre Homero e Proclus, Benoit faz uma escolha pela tautagoria, forma de leitura sem qualquer interpretação, que procura trazer apenas o que se manifesta em suas relações de superfície, em detrimento da interpretação alegórica, que procura uma outra coisa sob as coisas que se manifestam e um outro dizer com significado profundo. Benoit reconstrói historicamente a transformação do discurso autônomo, não instrumentalizado, em um discurso que passa a velar o mundo. Com o surgimento das formas mercantis, o logos deixa de ser parte da physis e exige técnicas de interpretação para a descoberta de significados profundos. A preocupação do autor é mostrar como, a partir do século $\mathrm{V}$ a.C., toda a tradição antiga é submetida à exegese alegórica, começando pelos mitos e poemas homéricos e chegando até Platão no neoplatonismo. Ele elege como exemplo dessa tradição exegética neoplatônica a leitura que Proclus faz de uma passagem da Ilíada, segundo a qual busca-se compreender a doutrina secreta sob os versos de Homero e absolvê-lo das acusações que Platão faz a ele na República. Para Proclus, as imitações poéticas escondem manifestações onto-teológicas e seu esforço corresponde à uma leitura de Homero à luz dos diálogos de Platão. Deve-se a Proclus também uma vasta interpretação onto-teológica dos diálogos, que Benoit considera tão arbitrária e fantasiosa quanto aquela dedicada a Homero.

Benoit denuncia, nas leituras de Proclus e de seus antecessores, as origens da interpretação de como Platão criador do mundo suprasensível, interpretação essa que surgiu às custas de sucessivas camadas de hermenênutica neoplatônica, e coloca em dúvida se as interpretações modernas e contemporâneas não trazem esse legado de mutilação da lexis platônica. O que Benoit propõe, então, é um grande trabalho arqueológico para fazer surgir o texto platônico mais próximo de Homero, fora do âmbito alegórico do neoplatonismo; propõe não priorizar a doutrina filosófica, a modo de Proclus, mas ler os diálogos como organismos internamente e externamente articulados.

O Capítulo 3, Uma obra sem autor e sem doutrina, é uma busca de Platão no interior dos seus próprios diálogos. Em uma época em que os gregos afirmavam a autoria de seus escritos, Platão está ausente dos diálogos, seja como autor, seja como defensor de uma doutrina. Seu nome aparece poucas vezes como personagem, porém de modo breve ou que às vezes, suspeita Benoit, se faz presente por sua ausência. Por isso, uma leitura com suspensão das suposições tomadas pela tradição como certezas irrefutáveis levará o leitor a ver que pouco resta da presença de Platão como identidade. Personagens como Sócrates, Crítias, Parmênides e o Estrangeiro de Eleia não são portadores da palavra de Platão e não há, nos diálogos, um único autor que centraliza uma doutrina positiva, coerente e sistemática, já que os diálogos são discursos

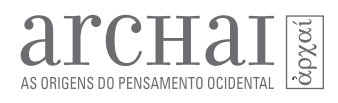

n. 16, jan.-apr. 2016

SOUZA, E. de, Benoit, H. (2015). Platão e as temporalidades: $a$ questão metodológica. São Paulo, Annablume.

p. $213-218$ 


\section{arcHaI \\ AS ORIGENS DO PENSAMENTO OCIDENTA}

n. 16, jan.-apr. 2016

SOUZA, E. de, Benoit, H. (2015). Platão e as temporalidades: $a$ questão metodológica. São Paulo, Annablume. p. 213-218 entrecruzados de múltiplos personagens e não podem expressar uma doutrina filosófica única.

O privilégio da fala de Sócrates, além de diversas estratégias que suprimem a dramaticidade do diálogo, transformaram o texto em monólogos e daí, explica o autor, se deduz uma "doutrina platônica" das ideias e, em torno dela, outros "dogmas", como a ideia de Bem, a oposição sensível-inteligível, a teoria da reminiscência, a teoria da mímesis que condena os poetas, a paideia platônica e o projeto de cidade ideal. A questão que Benoit levanta é: em que medida recortes de discursos de diversos personagens podem, de maneira legítima, ser tomados como a doutrina de Platão? Se hoje essa questão não faz sentido para os leitores e intérpretes, Benoit nota que a Antiguidade não teve tanta certeza a respeito da existência de uma doutrina platônica. Para mostrar isso, faz uma exposição de testemunhos antigos que negavam um Platão dogmático.

Uma leitura conceitualmente poética de Platão exige um olhar sem mediação da tradição, por isso o capítulo termina com uma introdução ao tema da temporalidade da lexis, mostrando que os personagens dos diálogos são marcados por esta temporalidade e não seres imutáveis como, em geral, tradição os representa. A maioria dos diálogos possuem demarcações temporais objetivas inscritas nos próprios textos, como fatos ou acontecimentos históricos, que os situam em certa diataxis ou disposição geral.

Segundo o autor, essas demarcações temporais já eram utilizadas em edições dos diálogos desde o século III a.C.. A primeira edição teria ordenado os textos em trilogias que obedeciam às demarcações lexicais. Benoit faz então um histórico da ordenação dos diálogos nas edições, que passam de trilogias para tetralogias, e salienta que até o século II d.C. a disposição era feita por demarcações lexicais, quando então passa a obedecer a uma nova ordem exigida por uma suposta “doutrina” de Platão. Só em 1920 a publicação da Société d'Édition "Les Belles Lettres" rompe com a tradição das tetralogias e passa a dispor os diálogos a partir do suposto tempo cronológico de produção da obra. Constrói-se, então, um Platão socrático, dos primeiros diálogos, e um Platão da maturidade, dos diálogos metafísicos. Desde 1950, o problema do ordenamento foi sendo abandonado como teoricamente irrelevante para a compreensão dos textos de Platão, com exceção das interpretações de Schleiermacher e Munk.

O capítulo 4, A diátaxis enquanto temporalidade da lexis, tenta encontrar a disposição dos diálogos a partir da lexis, sem qualquer interpretação. Entre os vinte e nove diálogos reconhecidos como autênticos, Benoit data com precisão dezenove diálogos entre os considerados mais importantes do ponto de vista do conteúdo da filosofia platônica e consegue uma datação aproximada dos outros. A disposição da temporalidade da lexis obedece uma periodização em cinco momentos. 
Após a exposição de seu trabalho de datação de cada diálogo, Benoit chega ao seguinte esquema geral da temporalidade da lexis: primeiro momento (450) - Parmênides; segundo momento (434 a 410) - Protágoras, Eutidemo, Lysis, Alcibíades I, Cármides, Górgias, Hipias Maior, Hipias Menor, Lákhes, Mênon, Banquete, Fedro; terceiro momento (410 a 399) - República, Timeu, Crítias, Filebo; quarto momento (399) - Teeteto, Eutífron, Crátilo, Sofista, Político, Apologia, Criton, Fédon; quinto momento (356-347) - Leis.

No capítulo 5, A lexis e outras temporalidades, Benoit reconhece, em Platão, além de uma temporalidade da lexis, outras três temporalidades que partem desta e se articulam: uma temporalidade da noesis, correspondente ao pensamento lógico-conceitual de Platão; uma temporalidade da genesis, correspondente aos acontecimentos que envolvem a história dos personagens, do pensamento e da história factual grega; e uma temporalidade da poiesis, correspondente à ação temporal de produção da obra, a sua cronologia.

Em geral, nota o autor, os comentadores privilegiam uma ou outra dessas temporalidades como filosoficamente pertinente. Sob essa perspectiva, faz críticas a tais comentadores, principalmente à corrente estruturalista de Victor Goldschimidt, que teria privilegiado a temporalidade lógico-conceitual.

A partir da temporalidade da lexis, seguindo o critério metodológico, pode-se chegar primeiramente à temporalidade lógico-conceitual de um modo não mais arbitrário, como aquele que propôs o estruturalismo. A disposição ordenada dos textos segundo a temporalidade da lexis poderia indicar a intencionalidade do autor, ou seja, a forma final através da qual Platão procurou ordenar seu logos. Teremos então o sentido de cada diálogo no tempo geral de sua obra. Assim, a temporalidade da lexis deve ser pensada como não meramente literária, sob o risco de alterar a temporalidade conceitual dos diálogos.

Depois de descobertas lexis e noesis, haverá a possibilidade de reconstruir (em maior ou menor medida) a temporalidade da genesis - a história biográfica de Platão - e daí se pode finalmente chegar à temporalidade da poiesis - a cronologia de sua obra. A ordem metodológica das temporalidades é lexis-noesis-gênesis-poiesis, embora a ordem objetiva de construção dos textos seja genesis-poiesis-noesis-lexis. A lexis deve ser sempre o ponto de partida metodológico para os leitores de Platão.

A temporalidade da lexis não pressupõe que o Platão tenha o projeto de sua obra acabado desde o começo. Benoit considera lexis e noesis como resultados de toda a produção do autor. Portanto, a temporalidade da genesis e a temporalidade da poiesis não coincidem com elas. Tanto lexis quanto noesis são posteriores às outras duas temporalidades porque, afirma, provavelmente somente no fim da sua produção Platão conseguiu decifrar o enigma do tempo conceitual de sua obra.

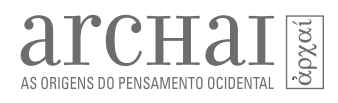

n. 16, jan.-apr. 2016

SOUZA, E. de, Benoit, H. (2015). Platão e as temporalidades: $a$ questão metodológica. São Paulo, Annablume.

p. $213-218$ 


\section{arcHaI圈}

n. 16, jan.-apr. 2016

SOUZA, E. de, Benoit, H. (2015). Platão e as temporalidades: $a$ questão metodológica. São Paulo, Annablume. p. 213-218
A publicação do livro se fazia necessária porque traz aos estudiosos em Platão e público em geral uma ideia que vem há anos influenciando alunos e colegas de Benoit. Também é um alerta para que o leitor de Platão questione se o Platão que está lendo não é um texto recortado e completamente afastado da cena dramática. Benoit provoca o leitor a ler o texto platônico na sua arquitetura e no seu movimento e mostra que Platão está muito além daquele filósofo dogmático dos dois mundos, que condenou o corpo, o amor e a arte. Ao sabermos a origem dessa interpretação, podemos colocá-la em dúvida e olhar o Platão criador de uma filosofia poética. Ao encontrarmos nos diálogos um sinal de que o pensamento de Platão só estava terminado depois de sua obra ter sido escrita, de que sua filosofia foi um pensamento dinâmico sempre em construção, não uma doutrina, podemos ler os diálogos sem procurar neles um sentido pré-determinado.

Há que ter o cuidado, no entanto, de não nos deixarmos tomar por um medo das interpretações a ponto de cair em uma espécie de ódio aos intérpretes, lembrando a misologia à qual Sócrates se refere no Fédon. A leitura de um texto antigo não é um fim em si mesmo, nem que tenha um objetivo de reconstrução histórica. Quando se trata de uma leitura filosófica, a leitura que se faz, as questões que se coloca, têm a ver com nossa realidade, por isso dependem de ferramentas hermenêuticas. Várias interpretações aproximam os problemas filosóficos levantados por Platão a problemas filosóficos atuais e é isso que move a discussão e faz com que Platão seja um filósofo estudado ainda hoje.

$\mathrm{O}$ que Benoit propõe, um trabalho liberto de toda e qualquer exegese, é um primeiro trabalho metodológico necessário ao exame dos diálogos. Minha dúvida, porém, é se deve ser definitivo ou se o trabalho metodológico de Benoit pode ser um guia para reconhecer uma boa interpretação, aquela que ajuda a refletir sobre Platão sem mutilá-lo. Talvez não seja impossível conciliar a leitura que Benoit nos proporciona com a leitura da vasta e importante pesquisa em Platão. Como Benoit mostra, Platão tem muitos logoi. Por que não pode ser lido de várias maneiras?

Submetido em Agosto e aprovado para publicação em Setembro, 2015. 